\title{
MINIFICCIÓN EN COLOMBIA. Aportes de Guillermo Bustamante Zamudio
}

\author{
Wilfredo José Rafael Illas Ramírez * \\ DOI: 10.33571/revistaluciernaga.v10n20a6
}

\section{Resumen}

Comprender el desarrollo de la minificción en Colombia, implica necesariamente detenerse en algunos nombres fundamentales que no solo se han consagrado a la producción literaria sino que su vocación hacia este género emergente, los ha llevado a examinar el terreno de la crítica, antología, teoría y difusión. Estos son los rasgos que además de definir el interés literario de Guillermo Bustamante Zamudio, se han constituido en su aporte más significativo a la evolución del género minificcional en Colombia y, por consiguiente, en Latinoamérica. Junto a ello, sus universos narrativos exploran atmósferas de ironía, humor, juego y parodia que devienen en la construcción de abismos en miniatura caracterizados por el absurdo, la fragmentariedad y lo trasgresor.

Palabras clave: Guillermo Bustamante Zamudio, desarrollo, minificción, Colombia

Recibido. Agosto 05, 2018

Aceptado. Agosto 30, 2018

*Profesor de Literatura (UPEL-IPB), Magíster en Literatura Venezolana (U.C), Especialista en Educación de Adultos (UNESR), Doctor en Educación (U.C-Venezuela), Postdoctor en Ciencias Humanas (LUZ), Postdoctor en Ciencias de la Educación (U.C). Doctor en Literatura Latinoamericana (U de C-Chile). Profesor Titular de la cátedra Teoría y Métodos de Investigación Literaria adscrito al Departamento de Lengua y Literatura de la Facultad de Ciencias de la Educación de la Universidad de CaraboboVenezuela. Director - Editor de la Revista de Postgrado Arjé adscrita a la FaCE-UC. Orcid: https://orcid.org/0000-0002-6550-3368; Email: illasw@hotmail.com 


\title{
MINIFICATION IN COLOMBIA. Contributions of Guillermo Bustamante Zamudio
}

\author{
Wilfredo José Rafael Illas Ramírez * \\ DOI: 10.33571/revistaluciernaga.v10n20a6
}

\section{Summary}

Understanding the development of minifiction in Colombia, it involves necessarily stop at some key names have not only devoted to the literary production but its vocation towards this emerging genre, has led them to examine the ground of criticism, anthology, theory and diffusion. These are the features that define the literary plus interest of Guillermo Bustamante Zamudio, have become its most significant to the evolution of the genre in Colombia minificcional contribution and therefore in Latin America. Along with this, their narrative universes explore atmospheres of irony, humor, playfulness and parody become chasms in building miniature characterized by absurdity, fragmentation and transgressive.

Keywords: Guillermo Bustamante Zamudio , development, minifiction , Colombia.

Received. August 05, 2018

Accepted. August 30, 2018

* Professor of Literature (UPEL-IPB), Master in Venezuelan Literature (U.C), Specialist in Education of Adults (UNESR), Doctor of Education (U.C-Venezuela), Postdoctor in Human Sciences (LUZ), Postdoctor in Education Sciences (U.C). Doctor in Latin American Literature (U of C-Chile).

Associate Professor of the Theory and Methods of Literary Research assigned to the Department of Language and Literature of the Faculty of Educational Sciences of the University of CaraboboVenezuela. Director - Editor of the Postgraduate Journal Arjé ascribed to FaCE-UC. Orcid: https://orcid.org/0000-0002-6550-3368; Email: illasw@hotmail.com 


\title{
MINIFICACÃO NA COLÔMBIA. Contribuiçổes de Guillermo Bustamante Zamudio
}

\author{
Wilfredo José Rafael Illas Ramírez * \\ DOI: 10.33571/revistaluciernaga.v10n20a6
}

\section{Resumo}

Entender o desenvolvimento da minificação na Colômbia envolve, necessariamente, insistir em alguns nomes fundamentais que não apenas se dedicaram à produção literária, mas também à sua vocação para esse gênero emergente, levando-os a examinar o terreno da crítica, antologia, teoria e difusão. Estas são as características que, além de definir o interesse literário de Guillermo Bustamante Zamudio, constituíram sua contribuição mais significativa para a evolução do gênero miniatura na Colômbia e, conseqüentemente, na América Latina. Junto a isso, seus universos narrativos exploram atmosferas de ironia, humor, brincadeira e paródia que se tornam a construção de abismos em miniatura caracterizados pelo absurdo, fragmentação e transgressão.

Palavras-chave: Guillermo Bustamante Zamudio, desenvolvimento, minificción, Colômbia

Recebido. Agosto 05, 2018

Aceitado. Agosto 30, 2018

* Professor de Literatura (UPEL-IPB), Mestre em Literatura Venezuelana (U.C), Especialista em Educação de Adultos (UNESR), Doutor em Educação (U.C-Venezuela), Pós-Doutor em Ciências Humanas (LUZ), Pós-Doutor em Ciências da Educação (U.C). Doutor em Literatura Latino-Americana (U de C-Chile). Professor Associado da Teoria e Métodos de Pesquisa Literária atribuído ao Departamento de Língua e Literatura da Faculdade de Ciências da Educação da Universidade de Carabobo.

Venezuela Diretor - Editor da Revista de Pós-Graduação Arjé atribuída à FaCE-UC. Orcid: https://orcid.org/0000-0002-6550-3368; Email: illasw@hotmail.comEmail: illasw@hotmail.com 


\section{Introducción}

Guillermo Bustamante Zamudio nació en Cali, Colombia en 1958. Es licenciado en literatura e idiomas por la Universidad de Santiago de Cali (1980) y Magíster en lingüística y español por la Universidad del Valle (1984). Actualmente es profesor de la Universidad Pedagógica Nacional de Colombia. Siendo aún estudiante universitario, funda, junto a Harold Kremer, la revista de minicuentos Ekuóreo y A la topa tolondra, ambas dedicadas a la difusión del ejercicio minificcional tanto en las letras colombianas como en el resto de la literatura latinoamericana.

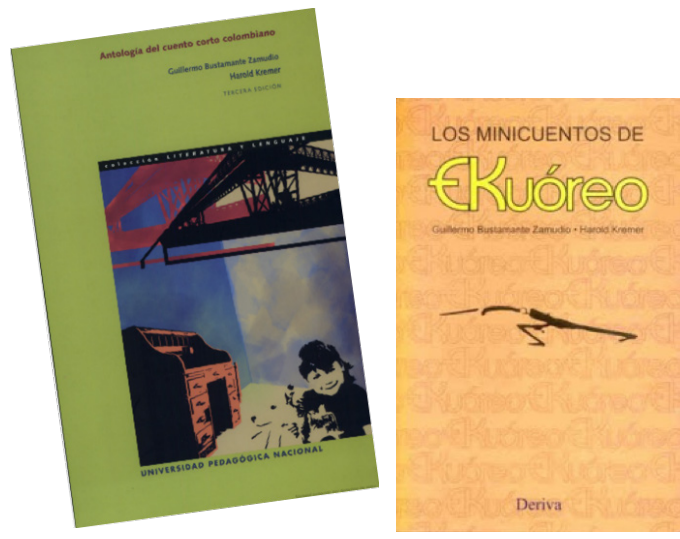

A estos inicios como promotor y difusor del género minificcional, le adviene una fecunda vocación de antologista, de la cual derivan tres importantes recopilaciones hechas en coautoría con Harold Kremer, las cuales demarcan más que una lista de obras y autores, un mapa, una ruta de lo que ha sido el desarrollo de la minificción en Colombia. Al abrigo de esta vocación, encontramos Antología del cuento corto colombiano (1994), en la cual figuran nombres fundamentales de la literatura colombiana y autores de referencia considerados precursores o primeros cultivadores del género minificcional, entre los que destacan: Jorge Gaitán Durán, Jorge Zalameda, Álvaro Cepeda Samudio, Luis Vidales,
Manuel Mejía Vallejo, entre otros notables exponentes de la literatura breve en colombia.

Los minicuentos de Ekuóreo(2003), libro recopilatorio de todos los textos minificcionales que encontraron un lugar en las publicaciones de Ekuóreo, revista que, según los teóricos e investigadores de la minificción, fue pionera tanto en el tratamiento especializado como en la difusión de la narrativa brevísima, no solo en Colombia, sino incluso, en Latinoamérica. Encontramos en esta antología, nombres fundamentales de la literatura universal $y$, dentro de esta, nombres de obligatoria referencia en la literatura latinoamericana y, por ende, en las letras colombianas, a saber:

Franz Kafka, Charles Baudelaire, José Donoso, Juan Carlos Onetti, Augusto Monterroso, Enrique Anderson Imbert, Hesíodo, Jorge Luis Borges, Virgilio, William Ospina, William Faulkner, Umberto Eco, Italo Calvino, Virginia Wolf, Julio Cortázar, Juan José Arreola, Vicente Huidobro, Ana María Shua, entre muchos otros.

Finalmente, tenemos la Segunda antología del cuento corto colombiano(2007), en la cual se rescatan más de cien trabajos no solo de los primeros cultivadores de la minificción colombiana, sino de voces nuevas que se han ido sumando en esa línea evolutiva, a la proliferación y expansión de la estética minificcional. Notables escritores colombianos como: Alfonso Castro, Álvaro Mutis, David Sánchez Juliao, Luz Marina "Nana" Rodríguez, Jairo Anibal Niño, son solo algunos de los nombres que engrosan una fecunda lista de autores, transeúntes, espectadores o habitantes, quizá, del universo minificcional. 


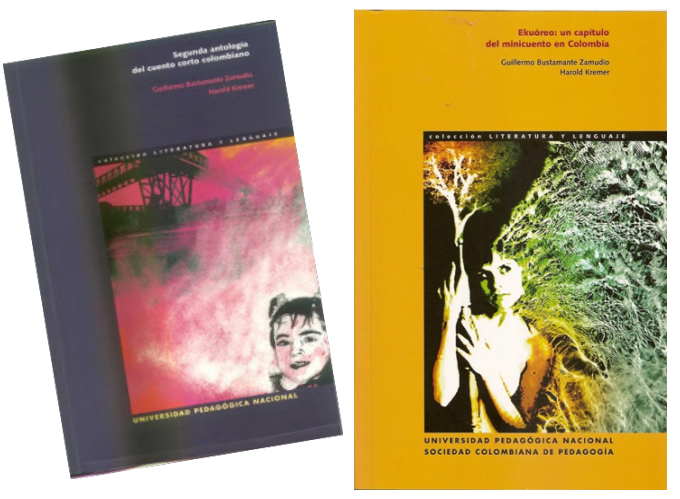

Junto a la producción de antologías, también con Harold Kremer, Guillermo Bustamante Zamudio presenta su trabajo de investigador recogido en el libro Ekuóreo: un capítulo del minicuento en Colombia (2008), cuyo libro no solo representó una recopilación de todas las ediciones de la revista Ekuóreo, sino un estudio que hundía sus propósitos en explorar el origen y desarrollo de la minificción en Colombia. Anécdotas, documentos y comentarios hacen de esta obra, un tránsito divertido por una historia que en paralelo sirve de pretexto para acercarnos al papel que jugó dicha revista en la difusión de la minificción, convirtiéndose más que en un capítulo del minicuento (o de la literatura breve), en otro elemento constitutivo que coadyuvó con el conocimiento de aquellas transiciones históricas y culturales que explicarían, por extensión, el desarrollo de la literatura colombiana contemporánea.

Por su parte, de su labor como escritor han derivado cuatro libros de narraciones minificcionales: Convicciones y otras debilidades mentales(2002), cuyo libro explora interesantes estrategias de experimentación que Bustamante Zamudio continuará practicando en sus posteriores producciones literarias, entre estas: el juego de palabras, la ironía, la parodia del mito cristiano, la integración de minificciones a partir de títulos o búsqueda temática, el espejo narrativo, el humor poniendo en tensión a la ciencia, el ejercicio reescritural de textos mitológicos o clásicos de la literatura universal y el desarrollo de un tejido lógico que permanentemente inquieta, impacta y golpea al lector:

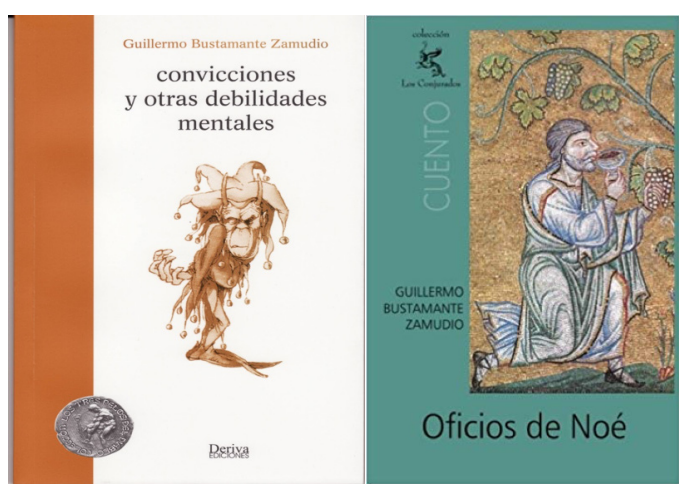

Sheherezada, Reina

La habilidad narrativa había salvado a Sheherezada de la costumbre capital del Califa. Su erotismo, presente ya en sus relatos, colmaba al Califa. Pero ella, que había contado una y mil veces las peripecias de las infidelidades, buscaba en las largas noches de palacio, insinuando su cuerpo lascivo, al sirviente que habría de satisfacerla secretamente. Cada vez, tras la batalla amorosa, pedía a su compañero que le narrara una historia entretenida. Siempre le causaba gracia no encontrar alguno que igualara su don narrativo. Siempre, inexplicablemente, se enfurecía y cortaba la cabeza de su amante. (p.14)

Es válido señalar que con este libro Bustamante Zamudio obtuvo el premio Jorge Isaacs (Valle del Cauca, Colombia) en su modalidad de cuento. Ya para el año 2005, nuestro escritor publica su libro Oficios de Noé, obra que explora no solo un interés reescritural alrededor de las peripecias del personaje bíblico, sino que apuesta por un conjunto de textos minificcionales que, en una suerte de integración temático-referencial, proyectan un conjunto unificado de historias, las cuales pueden ser leídas bien como pequeños y sueltos fragmentos narrativos o como una relación sucesiva de acontecimientos insospechados, simultáneos y miniaturizados que el autor construye en torno al mito cristiano del diluvio universal. Con respecto a este libro, afirma Dublín (2011) lo siguiente: 
En cada uno de los micros de este libro, el autor reinterpreta permanentemente los oficios, los cuestionamientos, las dudas, los sueños de Noé y le da una nueva dimensión a la historia del arca. De manera frecuente, diferentes escritores han relatado versiones de este personaje. Sin embargo, Bustamante Zamudio no se queda en una sola versión, sino en cerca de setenta para reinterpretar con ingenio literario el oficio de un personaje bíblico tan importante (...) Con Oficios de Noé, el autor le ofrece al lector perspectivas que se nutren de la ironía, el humor y la brevedad para lograr un libro con diferentes versiones alrededor de un mismo hecho... (p. $s / n)$

Su tercer libro de escritura minificcional es Roles publicado en el 2007, el cual fue merecedor de distinción, al obtener el premio del tercer concurso nacional de cuento, otorgado por la Universidad Industrial de Santander. Con este libro, el autor no solo continúa apostando por el absurdo, humor e ironía; sino que, siguen apareciendo pinceladas de reescritura en un amplio tapiz que exhibe con nitidez una búsqueda integrativa lograda, en esta oportunidad, por una lista de roles (la actriz, el guerrero, el creador, el enamorado, el filósofo, el narrador, el estudiante, entre otros) que, además de cohesionar el hilo discursivo de cada relato, sirve de pretexto para la parodia, reflexión y el sentido lúdico, rasgo este recurrente en la pluma de Bustamante Zamudio. En el acta que determina el veredicto y otorga la precitada presea al libro Roles, puede leerse:

En Roles no se narran historias en el sentido clásico y, a lo largo de esta apuesta narrativa, se privilegian opciones reflexivas y miradas que se distancian de las formas convencionales para provocar otra mirada sobre los temas que se abordan en estas apuestas narrativas. (2008: p.1)

Su cuarta y más recién producción literaria se titula Disposiciones y virtudes
(2016) es un libro compuesto por cien relatos minificcionales de variadas temáticas y estructurados en diversos géneros y formatos narrativos. Los juegos de palabras, el humor a extremo, la ironía conseguida por el estallido de parodia y absurdo, las posibilidades reescriturales y el afán de construir piezas sueltas que puedan ser integradas o cohesionadas en líneas temática-discursivas son solo algunos de los ingredientes con que Bustamante Zamudio vuelve a inquietar a sus lectores desde un conjunto de trampas que apuestan una vez más, por el juego, la reflexión y por una profunda indagación en que la brevedad se va haciendo infinita en cada experiencia de lectura.

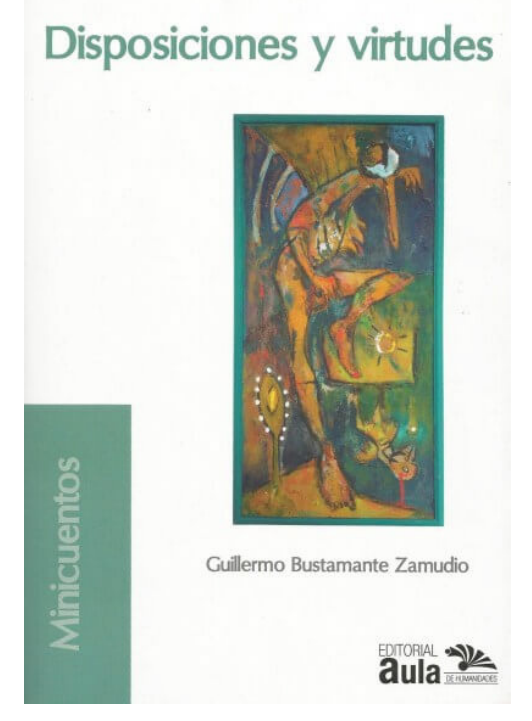

El libro se estructura en seis partes cuyos títulos actúan como elemento cohesionador de las minificciones a las que remite. Aquí la integración conseguida por los títulos, permite establecer puentes de unión entre los pequeños fragmentos narrativos que podrían tener suficiente autonomía para verse por separado; pero que, en la unidad, alcanzan un esplendor armónico de secuencia narrativa o de completa posibilidad ficcional, a través de una búsqueda metaficcional, intertextual y 
serial que configura el autor en la última parte del libro titulada Arte Poética y de la cual resulta a propósito revisar algunos ejemplos:

\section{Universo}

Como su nombre lo indica: poema de un solo verso.(p.96)

\section{Historia de la literatura}

Al principio era el verbo, de manera que hubo poesía. Luego hubo papel y hubo tiempo, de manera que grandes sagas fueron propicias para un mundo mitad desconocido, mitad inventado. Más tarde hubo imprenta, y hubo paciencia; ya casi todo estaba descubierto, de manera que hubo novela, saga del espíritu. Pero todo empezó a agotarse -el tiempo, el papel, la paciencia- , de manera que hubo cuentos, cada vez más cortos. Antes del final, sólo quedará el verbo y tal vez, de nuevo, la poesía. (p97)

\section{Postmodernidad}

Llegó el día en que cayeron los macrorrelatos: quedaron vueltos una miríada de microrrelatos. (p.102)

\section{Des(a)tino}

Cuando se conoce una novela por vez primera, la historia progresa de la mano del lector y los personajes enfrentan la apertura de caminos que cada opción edifica. En cambio, cuando la obra vuelve a ser leída, la historia se repite y así los personajes conocen de antemano el destino de los acontecimientos. Entonces ya no hay albedrío posible, pues el lector los obliga a tomar las decisiones que una y otra vez los conducen a las mismas fatalidades. (p.100).

Una vez presentada esta revisión panorámica de la trayectoria literaria de Guillermo Bustamante Zamudio, es pertinente agregar como dato adicional que sus producciones y aportes han encontrado acogida en diversas antologías y en numerosos estudios que, en torno al género, han hecho escritores e investigadores latinoamericanos. De esta forma, sus obras pueden leerse en la Revista latinoamericana de bibliografía (Washington, 1996), La minificción en Colombia (Bogotá, 2002), Dos veces bueno 3 (Buenos Aires, 2002), El placer de la brevedad: seis escritores de minificción y un dinosaurio sentado (Tunja, 2005); y, Nosotras, vosotras y ellas (Buenos Aires, 2006).

Finalmente, aunque es evidente que el objeto de estudio de este documento es la obra de Guillermo Bustamante Zamudio, el interés conceptual y metodológico se orienta fundamentalmente hacia su libro Oficios de Noé, básicamente por tres elementos generadores: por una parte el uso de referencias intertextuales que desembocan en un proyecto narrativo de aspiración reescritural; en segundo lugar, el interés de cohesión temática-discursiva que plantea la integración del fragmento minificcional en unidades amplias, seriales y cohesionadas que apuestan por la secuencialidad a partir de búsquedas narrativas condensadoras de lo fragmentario; y, por último, aunque el libro está compuesto de textos minificcionales, no todos comportan la misma estructura genérica, asumiendo entonces, una hibridez lograda a partir de diversos formatos narrativos que se acompaña de un conjunto de recursos capaces parodiar mitos y fórmulas, ironizar temáticas y creencias, jugar hasta estallar en risa y asombro. La arquitectura de todo este abismo minificcional se sustenta en tres instancias estéticas fundamentales: simultaneidad narrativa, carácter polisémico y universo miniaturizado.

Evidentemente la obra de este escritor no constituye, desde ningún punto de vista, un escenario acabado; sus creaciones suscitan multiplicidad de lecturas, su vocación minificcional se encuentra en pleno desarrollo y sus inclinaciones 
estéticas a la luz de su perfil escritural, en una dinámica de reinvenciones y experimentaciones, se encuentra en permanente reconstrucción. Todas estas razones también exigen la atención investigativa a una de las figuras más influyentes de la minificción en Colombia y, por extensión, a un incansable cultivador, investigador y difusor de este género en el contexto latinoamericano.

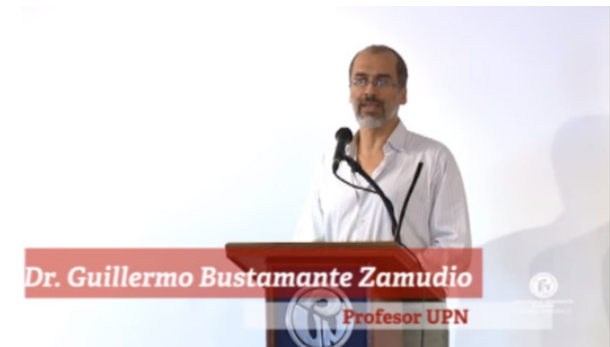

Tomado de:

https://www.youtube.com/watch?v=Tza5MtV-naA

\section{Aproximación al perfil literario de Guillermo Bustamante Zamudio}

Aunque la crítica especializada no le ha brindado suficiente atención a la figura de Bustamante Zamudio $y$, por consiguiente, no ha estudiado con rigurosidad su fecundo ejercicio estético en lo que es su propuesta escritural, es evidente que este escritor se ha ganado un lugar importante dentro del desarrollo de la minificción en Colombia no solo desde su vocación de antologista y crítico literario, sino desde el universo narrativo que construye alrededor de toda una estética de la brevedad signada por rutas insospechadas y por búsquedas narrativas que escudriñan nuevas posibilidades, las cuales definitivamente enriquecen el devenir de la minificción. Todo aquél que se acerque a comprender la evolución del género en Colombia, e incluso en Latinoamérica, tropezará por una u otra vía con el nombre de este creador que ha hecho de la brevedad, una vocación de vida.

Al referirse a Bustamante Zamudo, nos dice en una entrevista Marcos Fabián Herrera (2008) que el reino de este escritor es la brevedad y, al respecto, expresa lo siguiente:

Su vida es un largo periplo de consagración a algo escaso en palabras pero sustancial: el minicuento. Es junto a Harold Kremer, quien con más hondura y empecinamiento ha compilado la historiografía de la minificción en Colombia. Es autor de deleitosos libros consagrados a este género, al igual que de connotadas investigaciones sobre el ejercicio pedagógico en el país, y coautor de las dos Antologías del Cuento Corto Colombiano, con numerosas ediciones cada una de ellas. Codirigió las revistas Ekuòreo y $\mathrm{A}$ la topa tolondra, que concitaron a su alrededor a toda una horda de artesanos de la brevedad. Este Lacaniano y ex presidente de la Sociedad Colombiana de Psicoanálisis, es un obstinado rastreador de los entresijos de la creación y un hombre de gravedad filosófica. (p. s/n)

Ahora bien, para aproximarnos al universo escritural de Bustamante Zamudio, no hay nada más conveniente que acercarse a sus propias consideraciones, descripciones de lo que ha sido su vocación literaria, no para encontrar en sus palabras un ars poética - un manifiesto, más bien para contagiarnos de aquellos principios que han movido los hilos de sus motivaciones, búsquedas y necesidades; y como estas 
encuentran terreno fértil en una pasión narrativa orientada, desde siempre, a descubrir el abismo en miniatura que se expresa en la minificción, se teje en la literatura... y se esconde en la vida. En torno a sus precisiones teóricas vinculadas con la definición del género minificcional, afirma Bustamante Zamudio (1994) lo siguiente:

El cuento corto, cuento brevísimo, minificción o minicuento, es un género literario (...) es un híbrido que revela siempre una sorpresa o asombro. Su temática destaca anécdotas, sueños, sátiras, fantasías, humor, pasajes de la historia y la literatura, recrea y adapta fábulas y mitos antiguos.(...) Todo esto hace que el cuento corto sea de difícil clasificación.(...) En Colombia su origen es reciente. (pp. 9-10).

Esta aspiración conceptual constituye en Bustamante Zamudio un evidente interés que, trascendiendo las fronteras de la exclusiva teorización o difusión, se ha constituido en coordenada de su propia búsqueda artística, una aspiración que se materializa dentro de cada pieza minificcional con la que el escritor ha sembrado el fértil terreno de la actual literatura colombiana.

Las visiones que orbitan en relación al artista y a su búsqueda escritural, expresadas bien por la crítica o por el mismo escritor, resultan ser el pretexto propicio para acercarnos además, a lo que se ha expresado en torno a sus particulares propuestas literarias. Interesa en este punto, específicamente, rescatar las impresiones que surgieron de ese universo minificcional recogido en su libro Oficios de Noé. En este sentido, y haciendo referencia a las características, ejercicio estético y proyecto narrativo que logra desarrollar Bustamante Zamudio con esta creación, el escritor Pablo Montoya (2005) afirma en el prólogo del mismo texto, lo siguiente:

Noé es una figura capaz de resistir el tiempo y el olvido. (...) Pero Noé es dueño de un compromiso tan arduo de cumplir que merece, quizás más que otros personajes míticos, la admiración y la compasión.(...) Aproximar un personaje de estas dimensiones a las coordenadas de hoy es una labor compleja. Y hacerlo desde la literatura y, más todavía, desde el minicuento, es rozar el ámbito del riesgo. Para ello es menester que el escritor posea la permanente curiosidad por la historia, los juegos agudos de la reinterpretación y la polisemia (...) Guillermo Bustamante, por fortuna, reúne todas estas condiciones.(...) Oficios de Noé (...) es una obra que se apoya en la forma musical del tema y las variaciones. El tema marco que, al principio, es el relato del Noé bíblico reescrito por el autor. Y luego están las sesenta y ocho variaciones que discurren entre la imaginación de la fábula, la burla del dicho popular, la gravedad de la sentencia, la invención de la poética, los reclamos feministas, las implacables leyes de la selección natural (...) Por esta deliciosa y lúcida diversidad, incrustada en el mito y la modernidad, el Noé que otorga Bustamante es tan próximo a nosotros. (pp.5-6)

Esta acertada apreciación se desliza entre los atributos artísticos de Bustamante Zamudio y los rasgos estéticos que caracterizan a ese universo minificcional que recrea y se recrea a sí mismo, dentro del tapiz narrativo que configura al libro Oficios de Noé. Pero dejemos que sea el mismo Bustamante, a través de una entrevista concedida a Fredy Yezzed(2010), quien nos revele sus particulares búsquedas, motivaciones y experimentaciones que no solo signaron este desafío escritural, sino que además encontraron en las páginas de este libro, un lugar oportuno para su manifestación y maduración:

¿Qué lo llevó a recrear el mito de Noé en su último libro?

No sé. Estaba escribiendo Disposiciones y virtudes, un conjunto de minicuentos impíos, como reza el subtítulo de este libro inédito. Ese 
texto incluía unos cuantos relatos sobre Noé. Pues bien, Pablo Montoya (...)no pudo negarse, por asuntos de amistad, a leer una primera versión de Disposiciones y virtudes. El libro le pareció heterogéneo, y sugirió explorar, por ejemplo, el tema del diluvio. (...) Como su escritura era para mí intimidante, le creí: empecé esa tarea, que fue de un entusiasmo arrollador. Investigué, leí sobre las distintas versiones de la Biblia, el Noé del Corán, el diluvio entre las culturas indígenas de América, en la India, entre los caldeos, los griegos... Me entusiasmé mucho (...). Trabajaba muchísimo, vivía encantado escribiendo en cualquier parte, sobre cualquier trozo de papel. Supongo que por tener relación con la tradición bíblica (...). En ese contexto, contra todo pronóstico, un hombre salva a la humanidad: eso qué quiere decir; cuántos intríngulis hay en esa decisión, en el trasegar por los días de diluvio y después esperar a que todo resurja, pero nada; cuántas preguntas se pueden instalar en las cabezas de esos seres, empezando por Yavé... Trato de irme por ese camino y hacer saltos históricos con asuntos cotidianos de hoy, interpolados en esa época. En fin, no lo hago porque quiera escribir minicuentos, sino porque soy incapaz de escribir otra cosa. No sé si es buen libro, pero sí sé que está cruzado por un entusiasmo impresionante. (pp. 19-20).

Esta panorámica además de acercarnos a la figura de Bustamante Zamudio en relación a sus planteamientos teóricos y artísticos, nos permite conocer además las visiones de una crítica precedente que germina en torno al escritor y a su obra. Como valor agregado, nos permite ubicar a este escritor dentro de un contexto literario en el cual su vocación por la brevedad se emparenta a su necesidad expresiva. Es interesante acercarse a la sorpresa que suscita su obra en la que no sabemos si habitamos con él ese abismo en miniatura o somos parte de un arca que se mueve por el incierto derrotero, diluido o tal vez recreado, de su propio e incierto diluvio minificcional. Su obra continúa abierta a múltiples posibilidades de resignificación, su escritura sigue a la espera de atención crítica; su apuesta literaria, al acecho de esa reinvención constante, continuará siendo un terreno fértil para el ejercicio investigativo.

\section{Ideas (in) concluyentes. Lugar de Guillermo Bustamante Zamudio en el desarrollo de la minificción en Colombia}

El escritor e investigador colombiano Henry González en su trabajo El minicuento en la literatura colombiana (2002), hace un recuento de la génesis evolutiva de este reciente género. Aunque opta por el término minicuento, y sin entrar en polémicas alrededor de las diversas tipologías del relato breve, considera oportuno asumir dicho término como equivalente de minificción, a los efectos de este recuento histórico. Retomando los planteamientos de González (ob.cit), se asume que el minicuento colombiano consolidaría su devenir a través de cuatro momentos fundacionales:

\section{- Primer momento}

Aunque existen algunos ejemplos literarios que apostaban ya por una escritura minificcional hundiendo sus raíces para los años 1630 (caso de Juan Rodríguez Freyles, reseñado por González), no es sino hasta los años 1926, con la obra de Luis Vidales -según González (ob.cit)- que se instaura un momento fundacional en el cual ya se explora el ejercicio de la escritura breve. Específicamente en su libro Suenan timbres, Vidales no solo auspiciaba una exploración vanguardista que conectaría su escritura con un aliento estético de aspiración universal, sino que se apreciaba ya una inclinación hacia la brevedad como forma reconstructiva del universo dentro de la exploración estética - literarias. De Vidales nos dice González(ob.cit), lo siguiente:

Con su libro Suenan timbres(...) Vidales no solo se puso en sintonía con los vanguardistas del continente, sino que instauró en Colombia una escritura heteróclita, caracterizada por la extrema brevedad, el humor, la 
paradoja y la ironía(...) Lo que caracteriza a la estructura del texto es que la mayor parte de su contenido(...) está integrado por minificciones.(p.3)

\section{- Segundo momento}

Hasta los años 1970, González (ob.cit) considera que el ejercicio del minicuento tuvo una: "limitada atención y difusión"(p.4). Pese a que se continuó practicando, tuvo poco impacto en la búsqueda de lectores; sin embargo- nos dice el teórico- esto no impidió que voces como las de Jorge Gaitán, Manuel Mejía y Álvaro Cepeda Samudio consolidaran la práctica y la sucesiva publicación de minicuentos. A esta lista, la escritora e investigadora Nana Rodríguez (2006), reitera la mención de Luis Vidales como continuador de la escritura minicuentista e incorpora a Jorge Zalameda. En todos estos escritores, Rodríguez (ob.cit) destaca la vocación novelística que los impulsaba sin dejar de reconocer que también exploraron con espíritu aventurero el ejercicio de la cortedad a la luz de una aspiración poética que se imbricaría con el interés de lo fantástico para producir una forma de escritura experimental. Esta teórica, en consonancia con González y otros investigadores del género como Bustamante y Kremer (1994), considera que la práctica del minicuento durante este período, quedó relegada a una simple utilería que servía a periódicos y revistas, para rellenar esos pequeños espacios vacíos que restaban en algunas ediciones.

\section{- Tercer momento}

Los críticos e investigadores coinciden en que ya para la década del $70 \mathrm{se}$ consolida un auge de la escritura breve. No solo porque surgen nuevas voces y se multiplica la práctica de este ejercicio literario, sino porque entran en juego otros elementos que coadyuvan con la difusión de este joven género dentro de las páginas de la literatura colombiana. Para González (ob.cit) la regularidad en la producción artística minificcional, sumada a la difusión, al espíritu reivindicatorio de la cultura popular y del compromiso ante la problemática social; $y$, al cruce genérico que trascendía lo literario para instaurarse en otros discursos del arte y de la imagen demarcaron definitivamente un contexto exitoso para la escritura minificcional; por supuesto, todo ello albergado en un aliento epocal de referencia estética, ideológica y cultural.

Estos elementos (y quizá otras circunstancias) fueron ocasión propicia para un verdadero y consolidado desarrollo de esta práctica escritural durante casi veinte años, generando una especie de alumbramiento que ya no tendría retorno, una especie de oclusión exitosa y expansiva de esta estética minificcional que tomaría la mano de los escritores Daniel Sánchez Juliao (con su obra El arca de Noé: 1976), Jairo Anibal Niño con sus libros Toda la vida y Puro pueblo (1976), Elkin Obregón, entre otros connotados. Sin embargo, lo que más destaca González (ob.cit) para argumentar este desarrollo, fue la presencia de la Revista Ekuóreo, órgano que -según él- no solo auspició la creación y difundió la práctica escritural del minicuento, sino que se especializó en la recopilación de este tipo de productos literarios. En relación al papel que jugó la mencionada revista en el auge de la escritura minificcional, señala este investigador, lo siguiente:

Su entusiasta actividad durante algunos años no sólo llamaría la atención de muchos escritores y lectores colombianos, sino que trascendería las fronteras(...), el maestro Edmundo Valadés(...) hace referencia al papel pionero que la revista Ekuóreo cumplió con el fomento y difusión del minicuento en Colombia y señala cómo dicho papel estaba en sintonía con el auge que por aquella época había adquirido este tipo de creación en Hispanoamérica. Así Ekuóreo se constituía como un "órgano" de expresión que sintetizaba las nuevas formas de escritura liviana y versátil con que los escritores pretendían revelar una nueva sensibilidad estética (...) (pp. 4-5). 
Junto al aporte de Ekuóreo como órgano de promoción y difusión de la escritura minificcional, es conveniente reseñar dos aspectos que se constituyen fundamentales dentro de este estudio, para situar la trayectoria y búsqueda escritural de Guillermo Bustamante Zamudio. En primer lugar, Ekuóreo representa un punto de referencia obligatoria y una participación estelar dentro del desarrollo de la minificción colombiana. En sus iniciativas fundacionales $y$ en sus inquietudes estéticas, germina ya la vocación y el interés de este escritor por la brevedad narrativa. Es este el primer antecedente que vincula a Bustamante Zamudio con el ejercicio minificcional en cuanto a intereses, motivaciones, estímulos, influencias y formación de lo que posteriormente sería su propuesta literaria.

En segundo lugar, Ekuóreo - según críticos e investigadores- nace de una actitud de rebeldía, ruptura y renovación, búsquedas estas que González (ob.cit) reseña junto al interés humano, al ímpetu juvenil y al espíritu de lucha en "contra de los discursos estereotipados"(p.5). Este sería entonces nuestro segundo elemento contextual que nos permite advertir cómo la figura de Bustamante Zamudio se hace portavoz de una escritura subversiva (en cuanto a formas, géneros y temas) movida por ideales vinculados a la renovación estética que celebra la caída y la burla a partir de un lugar fronterizo, cuyo símbolo fundamental sería el fragmento, la ironía y el humor.

De esta forma, la época de Ekuóreo representó coincidencia o consecuencia de lo que posteriormente sería el florecimiento y la expansión de la minificción colombiana, época que por demás estuvo signada por la creación, difusión y, por un importante elemento que se adicionaba, la emergencia teórica del género minificcional. Estos elementos fueron orbitando alrededor de una idea puntual: "deslindarlo de otros géneros y fundar una poética del mismo en abierta pugna con el canon vigente" (González: ob.cit, p.5). Las coordenadas epistémicas que vieron surgir a Ekuóreo y que cimentaron las bases de su orientación fundacional, no son más que los intereses y propuestas que en relación bidireccional (crear y crearse), condicionaron el espíritu creativo de Bustamante Zamudio, quien, a partir de esta iniciativa editorial apoyada por Harold Kremer, alcanzaría para siempre un nombre y un lugar de referencia obligatoria, en la comprensión de lo que sería el surgimiento y la evolución del género minificcional dentro de los devenires que matizan la literatura colombiana.

Para Rodríguez (ob.cit), Ekuóreo además de ser la revista pionera en la difusión del minicuento en Colombia, fue el motor para que sus directores (Bustamante y Kremer) desarrollarán un fructífera labor como investigadores y recopiladores, cuya labor desembocó en un trabajo antologista que cimentó las bases para el conocimiento, práctica y configuración literaria del joven género minificcional. Al referirse, esta investigadora, a la Antología del cuento corto colombiano, lograda por la dupla Bustamante-Kremer, plantea lo siguiente: "Dentro de esta antología se encuentran las más variadas formas como la re-creación del mito, la parodia bíblica, los relatos fantásticos; y como características, el humor negro, la ironía y la parodia, las anécdotas cotidianas, los finales sorprendentes".(p.47)

Obsérvese que el interés de Bustamante Zamudio por antologar textos que expresaban esos rasgos característicos reseñados por Rodríguez, revelaba, de alguna forma, ya no solo su interés por esta apuesta escritural, sino que vaticinaba lo que serían sus búsquedas, inclinaciones y estrategias (bien desde la motivación, influencia o continuación) en la gestión de su propio desempeño artístico. Así, al interés por el texto minificcional y al espíritu de reacción y ruptura, se sumaría este tercer vínculo, expresado en la cercanía (amparada en una clara influencia y predilección) de nuestro escritor con un conjunto de temas y fórmulas estéticas de la minificción, que definirían su particular estilo literario y le sellarían una lúcida y consistente vocación minificcional que sería desde ya una línea distintiva de su producción artística. 


\section{- Cuarto momento}

A fines del siglo $X X$ e inicios del $X X I$, el minicuento en Colombia ha alcanzado un pleno desarrollo, expresado, de acuerdo a los investigadores y rastreadores históricos del género, por: reconocimiento, acogida cultural, amplitud de publicaciones, aumento de revistas y concursos dedicados al estímulo de la producción minificcional, importancia que se la ha atribuido a la brevedad narrativa tanto en el ámbito académico como en el cultural, incremento de la reflexión y búsqueda teórica y, florecimiento de numerosas antologías.

Progresivamente, se han ido sumando nuevas voces a la escritura minificcional, lo que significa una amplitud considerable de intereses, temas y exploraciones estéticas que se desplazan del interés reflexivo al sarcasmo extremo, del erotismo al desencuentro, de la reescritura mítica a la realidad virtual, del retorno a las fábulas hasta el asunto cotidiano o la vida nacional, en fin, una variedad temática en la cual lo único intacto es el apego por la parodia, ironía, el humor, absurdo; y, todo ello movido por un aliento estético de ruptura que desemboca en una escritura breve, fronteriza y polisémica.

En cuanto al asunto de las nuevas voces, resultan a propósito las consideraciones de González (ob.cit), quien al respecto, formula el siguiente planteamiento:

En la parte inventiva se aprecia el cruce de dos generaciones de minicuentistas. La primera está constituida por los ya consagrados y reconocidos (...) Celso Román, Triunfo Arciniegas (...) Jaime Castaño, Guillermo Velásquez, Juan Carlos Botero, Carlos Flaminio Rivera, Nicolás Suescún, Luis Fayad, Marco Tulio Aguilera, Juan Carlos Moyano (...) entre otros, quienes continúan en plena actividad. A la par de ellos se encuentran autores de publicación reciente como Nana Rocríguez, Pablo Montoya, Guillermo Bustamante, Gabriel Pabón (...) y muchos más, quienes harían esta lista sumamente amplia. (p.6)

Hay dos datos interesantes en este planteamiento. Por un lado, ya figura en la lista de los cultivadores de la minificción colombiana, nuestro escritor Bustamante Zamudio dentro de lo que será esa nueva generación de escritores dedicados al ejercicio de la escritura minificcional. $Y$, por el otro, observamos cómo su propuesta literaria se corresponde con una práctica escritural emergente que convoca en su ejercicio un cruce generacional, lo que permite reconocer un cuarto vínculo (en este caso producto de lo que sería una posible influencia estética) entre Bustamante y la minificción.

En torno al abanico temático en que se mueve el minicuento durante este cuarto momento, resulta legítimo asumir un quinto vínculo de relación entre nuestro escritor y la brevedad narrativa; y es que, su escritura se mueve alrededor de un amplio margen de temas, dispuestos además, por un marcado interés integrativo en el cual, los pequeños fragmentos se cohesionan por un pretexto de unidad que en su esencia remite a la ironía, lo paródico y el humor como únicas posibilidades para salir ileso de esos abismos en miniatura.

De esta forma, las búsquedas conceptuales y estéticas en este período de desarrollo y consolidación del género minificcional, no solo son los rasgos distintivos que Bustamante Zamudio expresa en su obra, también representan su aporte desde un aliento de exploraciones, experimentaciones y propuestas literarias que maduran en su escritura y coadyuvan con el auge de la minificción.

En cuanto al marcado interés integrativo e intertextual; $y$, a propósito de esta aproximación contextual que demarcaría por consiguiente un sexto vínculo entre el autor y la minificción, Rodríguez (ob.cit) señala que hay ejemplos (en lo que sería este cuarto período evolutivo) de autores, cuyas búsquedas y experimentaciones apuntaron a la escritura de minificciones integradas y ciclos de minificción. 
Esto se dio como expresión de nuevas prácticas escriturales que demarcaban diversos rumbos en el devenir del género en Colombia. Para esta investigadora, el ejercicio que procuraba la unidad del fragmento -o escritura serial según Zavala (2005)-, fue practicado inicialmente por escritores como Nicolás Suescún, Héctor Abad Faciolince, Rodrigo Argüello y Guillermo Velásquez.

Alrededor de esa búsqueda de unidad narrativa y, a propósito de la obra de los precitados escritores, Rodríguez (ob.cit) le atribuye a las propuestas de escritura serial que emergen en el universo minificcional, los siguientes rasgos característicos:

(...) No existe la secuencialidad, no hay comienzo ni fin, cualquiera de estos fragmentos tienen autonomía y unidad por sí mismos, son como un mosaico en el que cada pieza tiene como hilo conductor a (un) personaje (...) rompen los cánones establecidos para el género novela, (...) dentro de su carácter fragmentario, se pueden considerar varios minicuentos dentro de su estructura (...)es evidente la ironía, la poesía y las referencias intertextuales(...)(pp. 17-12)

Estas pinceladas características que pueden ser perfectamente reconocidas en la obra de Bustamante Zamudio, nos permiten inferir su recurrente práctica y su aguda predilección o fascinación por una escritura fragmentaria que se consolida en proyectos más amplios de integración $\circ$ de interés serial, regularmente, a partir de propuestas intertextuales en las que son parodiados, con una importante carga de ironía y humor, personajes y acontecimientos conocidos.

Cada fragmento es una instantánea (muchas veces absurda) que atrapa el momento y lo hace estallar en finales sorprendentes, logrados desde una interesante elaboración literaria caracterizada por el ingenio, el juego y la riqueza del lenguaje. Ahora bien, esta panorámica nos conecta con un dato adicional, al no ser una propuesta exclusiva de nuestro escritor, es viable observar que el experimento de unidad narrativa que vendría a cohesionar el fragmento minificcional, deriva de una inquietud generacional que se mueve en torno a nuevas rutas estéticas de exploración narrativa, las cuales son inherentes a la propia dinámica evolutiva que constantemente está reinventándose dentro del universo minificcional.

Para cerrar este apartado y, en relación a lo que ha sido el desarrollo del minicuento en Colombia durante este cuarto momento, Rodríguez (ob.cit), en consonancia con los aportes de González, plantea lo siguiente:

Como se puede notar, en la década de los noventa e inicios del tercer milenio, la producción editorial del minicuento en Colombia, es considerable, comparada con las décadas anteriores. Las tendencias por la brevedad, la prosa poética, la elipsis, la fractalidad, los recursos intertextuales, los libros híbridos, la presencia de los concursos, nos demuestran como lo han dicho en otras instancias, que el minicuento goza de muy buena salud.(...) si tuviéramos que hablar de una identidad o una constante en la temática, es indudable, la presencia de una temática apocalíptica, una estética del horror y la muerte, un humor negro frente a las fatalidades del país, pero de igual manera encontramos una vertiente que explora la ironía fina, la sonrisa cómplice, un diálogo entre textos, algunos rasgos posmodernos en la escritura y sobre todo, la presencia de la poesía. (...)Para concluir, se puede decir que el futuro del minicuento y la minificción en Colombia es prometedor. (pp. 57-58)

Es evidente que en esta realidad de florecimiento y expansión, sea complejo comprender, y más aún, intentar predecir el devenir del género minificcional en Colombia, bien por la diversidad de temas, multiplicidad de formas o abundante producción artística que 
progresivamente va adquiriendo dicho género; o bien por la cantidad de voces que, de manera permanente y sostenida, se van sumando a su práctica, cada una desde la especificidad propia de su estilo, propuesta y experimentación.

El amplio desarrollo de la minificción en Latinoamérica, hace necesaria la existencia de una rigurosa actividad investigativa que, en muchos casos, deberá transgredir (o trascender) los cánones y dogmas, para adecuarse a la comprensión de un género en el que no hay fórmula, sino más bien un terreno de producción desde el cual se encuentran (o del que deberán extraerse) los propios mecanismos para su recepción. Desde el lugar fecundo de su práctica, también podemos acercarnos a las particularidades que van delineando los rasgos caracterizadores del texto minificcional. Se trata entonces de advertir la necesidad de una crítica especializada capaz de examinar con amplitud, la proyección y expansión que paulatinamente ha ido legitimando el auge de la minificción, tanto en las letras colombianas como en el resto de la literatura latinoamericana. Espacio que, por cierto, se ha constituido en terreno fértil y predilecto para el surgimiento, desarrollo y expansión del género minificcional.

\section{Bibliografía}

- Bustamante, G. (2002). Convicciones y otras debilidades mentales. 1era. Edición. Cali: Deriva ediciones.

- Bustamante, G. (2005). Oficios de Noé. lera. Edición. Bogotá: Común presencia editores.

- Bustamante, G. (2007). Roles. 1era. Edición. Bucaramanga: Fondo editorial Universidad Industrial de Santander.

- Bustamante, G. (2016). Disposiciones y virtudes. lera. Edición. Cali: Deriva ediciones.

- Bustamante, Z, y Kremer, H. (1994). Antología de cuento corto colombiano. lera. Edición. Bogotá: Fondo editorial Universidad Pedagógica Nacional.

- Bustamante, Z, y Kremer, H. (2003). Los minicuentos de Ekuóreo. 1era. Edición. Cali: Deriva ediciones.

- Bustamante, Z, y Kremer, H. (2007). Segunda antología del cuento corto colombiano. lera. Edición. Bogotá: Fondo editorial Universidad Pedagógica Nacional.

- Bustamante, Z, y Kremer, H. (2008). Ekuóreo: Un capítulo del minicuento en Colombia. lera. Edición.Bogotá: Fondo editorial Universidad Pedagógica Nacional.

\section{Para citar este artículo:}

Illas - Ramírez, W. (2018). MINIFICCIÓN EN COLOMBIA. Aportes de Guillermo Bustamante Zamudio. Revista Luciérnaga / Comunicación. Año 10, № 20 Págs. 98 - 112

DOI: 10.33571/revistaluciernaga.v10n20a6

OJS. http://revistas.elpoli.edu.co/index.php/luc/issue/archive

Link. https://www.politecnicojic.edu.co/index.php/revista-luciernaga
- Dublín, E. (2011) "El arca de Bustamante Zamudio". Internacional microcuentista. Documento digitalizado en http://revistamicrorrelatos.blogspot.cl/2011/01/elarca-de-bustamante-zamudio.html (Consulta 03/03/2016)

- González, H. (2002). "El minicuento en la literatura colombiana". Folios, 15. Documento digitalizado en

https://doi.org/10.17227/01234870.15folios45.51. (Consulta 05/02/2016)

- Herrera, M. (2008). "El reino de la brevedad. Entrevista a Guillermo Bustamante Zamudio". Revista electrónica Con-fabulación, número 52. Documento digitalizado en: http://carmencamachoadarve.blogia.com/2008 /081701-entrevista-a-guillermo-bustamante-zamu dio-por-marcos-fabian-herrera.php (Consulta 08/03/2016)

- Rodríguez, N. (2006). "El minicuento en Colombia". Cuadernos de lingüística hispánica, número7, pp.43-60

- Yezzed, F. (2010). "Guillermo Bustamante Zamudio: juzgar algo por la extensión en literatura no tiene sentido. Entrevista". Plesiosaurio, III, 3, pp.13-23

- Zavala, L. (2005). La minificción bajo el microscopio. lera. Edición. Bogotá: Fondo editorial Universidad Pedagógica Nacional. 